OPEN ACCESS

Edited by:

Gul Dolen,

Johns Hopkins University, USA

Reviewed by:

Marc Fuccillo,

University of Pennsylvania, USA

Mollie Meffert,

Johns Hopkins School of Medicine,

USA

*Correspondence: Yi-Ping Hsueh

yph@gate.sinica.edu.tw

Specialty section:

This article was submitted to

Systems Biology,

a section of the journal

Frontiers in Neuroscience

Received: 29 April 2015 Accepted: 12 October 2015 Published: 03 November 2015

Citation:

Huang T-N and Hsueh Y-P (2015)

Brain-specific transcriptional regulator

T-brain-1 controls brain wiring and

neuronal activity in autism spectrum

disorders. Front. Neurosci. 9:406

doi: 10.3389/fnins.2015.00406

\section{Brain-specific transcriptional regulator T-brain-1 controls brain wiring and neuronal activity in autism spectrum disorders}

\author{
Tzyy-Nan Huang and Yi-Ping Hsueh * \\ Institute of Molecular Biology, Academia Sinica, Taipei, Taiwan
}

T-brain-1 (TBR1) is a brain-specific T-box transcription factor. In 1995, Tbr1 was first identified from a subtractive hybridization that compared mouse embryonic and adult telencephalons. Previous studies of Tbr1-/- mice have indicated critical roles for TBR1 in the development of the cerebral cortex, amygdala, and olfactory bulb. Neuronal migration and axonal projection are two important developmental features controlled by TBR1. Recently, recurrent de novo disruptive mutations in the TBR1 gene have been found in patients with autism spectrum disorders (ASDs). Human genetic studies have identified TBR1 as a high-confidence risk factor for ASDs. Because only one allele of the TBR1 gene is mutated in these patients, $\mathrm{Tbr} 1^{+/-}$mice serve as a good genetic mouse model to explore the mechanism by which de novo TBR1 mutation leads to ASDs. Although neuronal migration and axonal projection defects of cerebral cortex are the most prominent phenotypes in $\mathrm{Tbr} 1^{-/-}$mice, these features are not found in Tbr1 ${ }^{+/-}$mice. Instead, inter- and intra-amygdalar axonal projections and NMDAR expression and activity in amygdala are particularly susceptible to Tbr1 haploinsufficiency. The studies indicated that both abnormal brain wiring (abnormal amygdalar connections) and excitation/inhibition imbalance (NMDAR hypoactivity), two prominent models for ASD etiology, are present in Tbr1+/- mice. Moreover, calcium/calmodulin-dependent serine protein kinase (CASK) was found to interact with TBR1. The CASK-TBR1 complex had been shown to directly bind the promoter of the Grin2b gene, which is also known as Nmdar2b, and upregulate Grin2b expression. This molecular function of TBR1 provides an explanation for NMDAR hypoactivity in $T b r 1^{+/-}$mice. In addition to Grin2b, cell adhesion molecules -including Ntng1, Cdh8, and Cntn2 - are also regulated by TBR1 to control axonal projections of amygdala. Taken together, the studies of Tbr1 provide an integrated picture of ASD etiology at the cellular and circuit levels.

Keywords: amygdala, axonal projection, autism, cerebral cortex, intellectual disability, neural circuit, neurodevelopmental disorders, TBR1 


\section{INTRODUCTION}

Autism spectrum disorders (ASDs) are heterogeneous and highly heritable neuropsychiatric disorders. Hundreds of genes with de novo copy-number variations or de novo point mutations have been identified in thousands of patients with ASDs (Gilman et al., 2011; Neale et al., 2012; O'roak et al., 2012a,b; De Rubeis et al., 2014; Iossifov et al., 2014). Although this variety of ASDassociated genes reflects the high heterogeneity of ASDs, $\sim 26$ high-confidence risk genes for ASDs have been summarized from large scale whole-exome sequencing (O'roak et al., 2012a; De Rubeis et al., 2014; Table 1). Among these high-confidence risk genes, 11 encode either transcription factors or chromatin remodeling factors, indicating that the dysregulation of gene expression is a common pathogenic mechanism for ASDs (Table 1). To date, T-BRAIN-1 (TBR-1) is the best studied transcription regulator among the high-confidence risk genes for ASDs. In this review, we summarize the physiological functions of TBR1 and the currently understood mechanisms by which TBR1 mutations cause ASDs. Based on the data accumulated from the mouse model, we suggest that abnormal brain wiring and reduced neuronal activity in the amygdala are the primary causes for TBR1-dependent ASDs.

\section{IDENTIFICATION OF TBR1 IN THE REGULATION OF BRAIN DEVELOPMENT}

TBR1 contains a T-box DNA binding domain (Figure 1) and belongs to the T-box transcription factor family (Papaioannou, 2014). Twenty years ago, Dr. John Rubenstein's laboratory first identified Tbrl from a subtractive hybridization screen using cDNA libraries made from mouse embryonic day 14.5 (E14.5) and adult telencephalons (Bulfone et al., 1995). Tbr1 mRNA levels were approximately 10 -fold higher in E14.5 telencephalons than in adult telencephalons (Bulfone et al., 1995), suggesting a role for TBR1 in brain development. In situ hybridization and immunofluorescence staining indicate that Tbr1 is expressed in the postmitotic neurons of the cerebral cortex, hippocampus, olfactory bulb and amygdala at the embryonic stages (Bulfone et al., 1995, 1998; Remedios et al., 2007; Huang et al., 2014). Using markers of projection neurons, including glutamate and CaMKII, TBR1 has been found to be further restricted to the projection neurons of the cerebral cortex, amygdala and olfactory bulb (Bulfone et al., 1998; Hevner et al., 2001; Huang et al., 2014). In the cerebral cortex, layer 6 neurons express the highest levels of TBR1. Projection neurons in the remaining layers also express TBR1, though the expression levels are lower

TABLE 1 | High-confidence risk factors for ASDs.

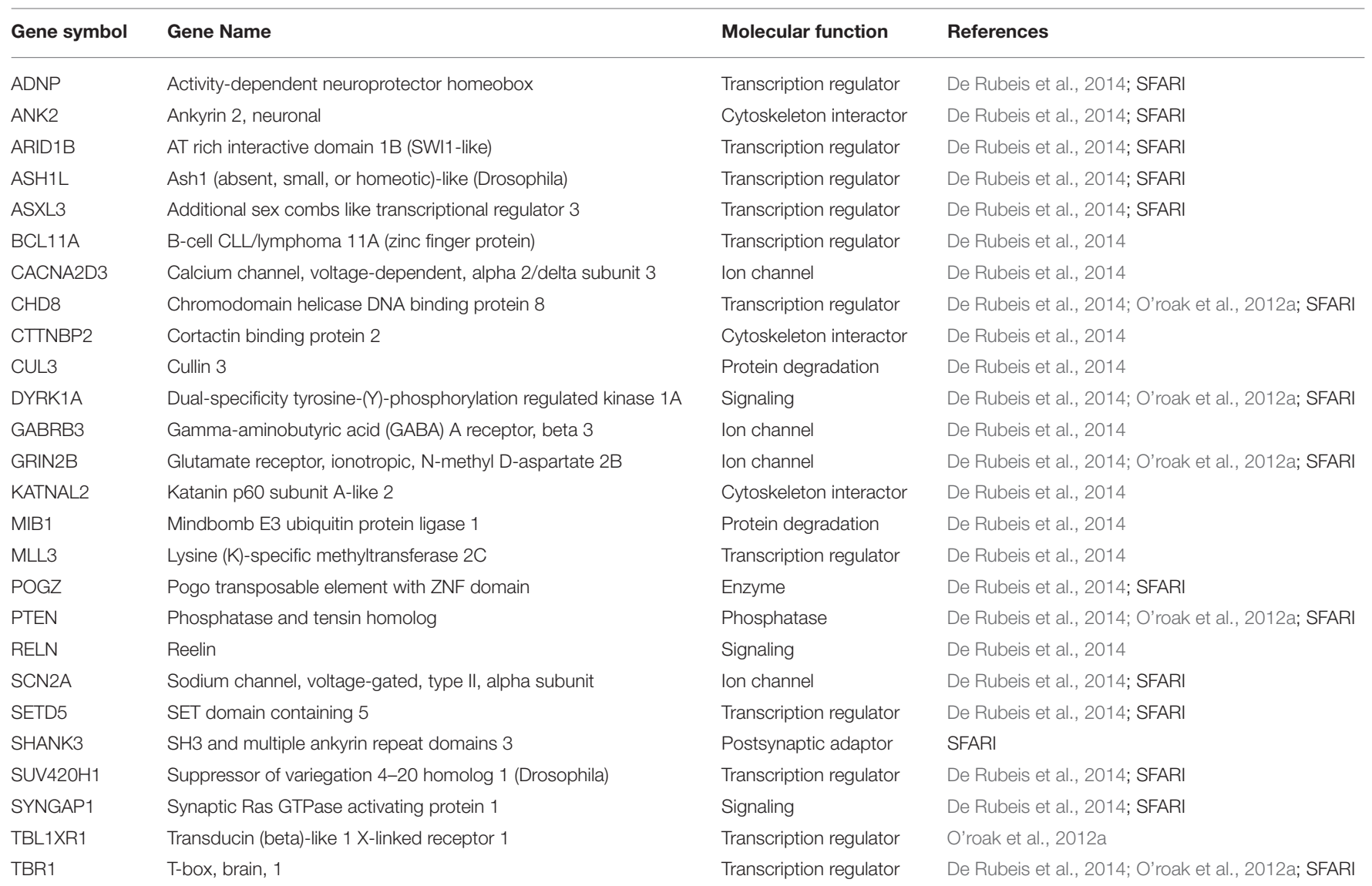




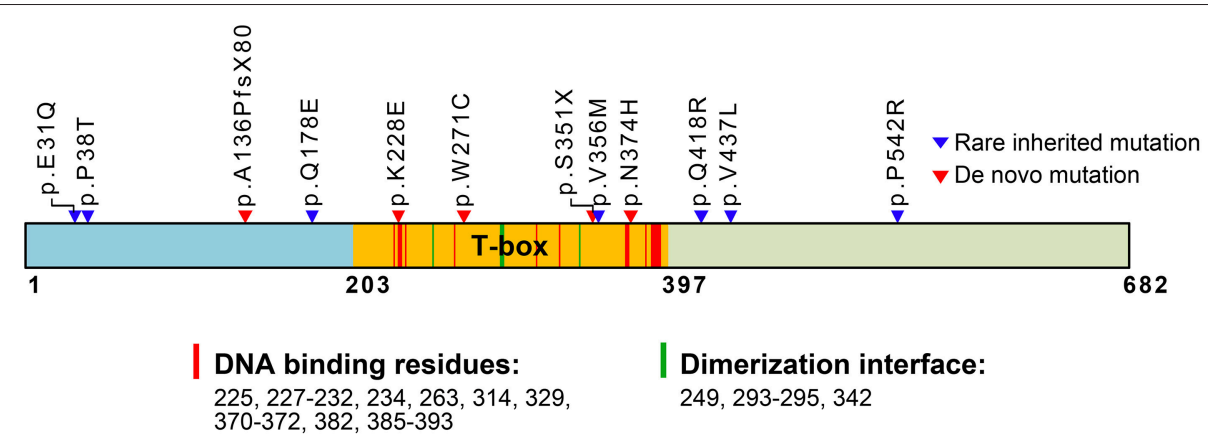

FIGURE 1 | Schematic domain structure of TBR1 and identified mutations in patients with ASDs. The T-box DNA binding domain extends from amino acid (aa) residue 203-397. The predicted aa residues for DNA binding and dimerization based on the T-box structure of Brachyury (T protein) are also indicated and labeled with red and green strips in the T-box. The positions of de novo mutations are labeled with red triangles; the positions of rare inherited mutations are labeled with blue triangles. The functions of the residues in the T-box are predicted based on comparison with the Brachury T-box (pfam00907: T-box, http://www.ncbi.nlm.nih.gov/ Structure/cdd/cddsrv.cgi?uid=250216).

(Hevner et al., 2001). In the amygdala, TBR1 is only expressed in the projection neurons of the lateral and basal amygdala (Huang et al., 2014). These studies clearly show that TBR1 is a projection neuron-specific T-box factor highly enriched in embryonic telencephalons.

Dr. John Rubenstein and colleagues generated $\mathrm{Tbr} \mathrm{I}^{-/-}$mice to investigate the physiological function of Tbr1 (Bulfone et al., 1998; Hevner et al., 2001). A homozygous deficiency of Tbr1 results in neonatal lethality within 1-2 days after birth, indicating that $T b r 1$ is essential for survival. Most projection neurons in the olfactory bulb, including mitral and tufted cells, and axonal output to the lateral olfactory tract are lost in $\mathrm{TbrI}^{-/-}$mice (Bulfone et al., 1998). In the cerebral cortex, the inside-out pattern of neuronal migration is completely disrupted, as the sixlayer laminar structure of the cortex is disorganized. Moreover, the contralateral axonal projections of the cerebral cortex and both corticothalamic and thalamocortical axonal projections are also defective, since they end mid-way to their final destinations in $\mathrm{Tbr}^{-/-}$mice (Hevner et al., 2001). TBR1 is also required for neuronal migration in the amygdala. A portion of the dorsal pallium that migrates from the caudal telencephalon pole toward the rostral telencephalon forms the basal and lateral amygdala. In $\mathrm{Tbr1}^{-/-}$mice, this caudal-to-rostral migration is disrupted and thus impairs amygdala development (Remedios et al., 2007). Although TBR1 is also expressed in the hippocampus, its importance in hippocampus development and function remains unclear.

Based on the studies using Tbr1 $1^{-/-}$mice, it is clear that TBR1 is critical for development of projection neurons in the cerebral cortex, olfactory bulb and amygdala.

\section{TBR1 DOWNSTREAM TARGET GENES}

Target genes of the TBR1 transcription factor were first identified by searching a database using the target sequence of the $\mathrm{T}$ box DNA binding domain (Hsueh et al., 2000; Wang et al., 2004a,c). Because members of the T-box protein family share a DNA binding sequence, this method cannot ensure that the target genes are specific for TBR1. Because TBR1 is neuronspecific, neuronal expression is the first criterion to further screen the TBR1 target genes identified from sequence analysis. Results of an electrophoretic mobility shift assay, chromatin immunoprecipitation and a luciferase reporter assay have shown that TBR1 directly binds to the promoters and regulates the promoter activity of Grin $2 b$ (Glutamate receptor, ionotropic, $N$ methyl-aspartate $2 b$, also known as Nmdar2b) and Reln (Reelin) (Hsueh et al., 2000; Wang et al., 2004a,c). Changes in RELN and NMDAR2B protein levels have also been confirmed in $T b r 1^{-/-}$ mice (Hevner et al., 2001; Wang et al., 2004c). Because Reln encodes an extracellular protein that is critical for neuronal migration (Martinez-Cerdeno and Noctor, 2014; Ohshima, 2014; Sekine et al., 2014), regulation of Reln expression by TBR1 could explain the migration phenotype in $T b r 1^{-/-}$mice. Regulation of Grin $2 b$ expression by TBR 1 is critical for neuronal activation, which we discuss further in a later section.

Both our and Dr. Robert Hevner's laboratories independently applied microarray analyses to identify TBR1 downstream genes. Using E14.5 and P0.5 mouse brains, Dr. Hevner's laboratory focused on the arealization and lamination of the cerebral cortex (Bedogni et al., 2010). Tbr1 exhibits a high rostral and low caudal expression pattern in the cortex (Bulfone et al., 1995). At both E14.5 and P0.5, a Tbr1 deletion noticeably alters the expression of regional markers. In general, rostral genes are downregulated in $\operatorname{Tbr}^{-/-}$brains, while caudal genes are upregulated. For cortical layer markers, most markers of layer 6, subplate and Cajal-Retzius cells exhibit noticeably reduced expression levels in $\mathrm{Tbr1}^{-/-}$brains. The majority of layer 2-5 markers are upregulated (Bedogni et al., 2010). The markers of lamination and arealization whose expression levels are altered in $\mathrm{Tbr} \mathrm{I}^{-/-}$ brains are listed in Table 2 . These studies indicate that TBR1 is critical for controlling the neuronal specification of the cerebral cortex.

In our laboratory, we have identified more than 124 genes that are regulated by TBR1 at E16.5 (Huang et al., 2014; Chuang et al., 2015). The 16 region- or layer-specific genes presented in work by Bedogni et al. (2010) from Dr. Hevner's 
TABLE 2 | Tbr1 deletion alters expression of genes with layer- or region-specific distribution in the cerebral cortex.

\begin{tabular}{|c|c|c|c|}
\hline Gene symbol* & Gene name & Layer & Region \\
\hline Bhlhb5 (BHLHE22) & Basic helix-loop-helix family, member e22 & L5 & Caudomedial \\
\hline Calb2 & Calbindin 2 & Cajal-Retzius & All \\
\hline Cdh8* & Cadherin 8, type 2 & L5 & Rostral + caudal \\
\hline Cdh9 & Cadherin 9, type 2 (T1-cadherin) & L6 & Rostral \\
\hline Cntn3 & Contactin 3 (plasmacytoma associated) & L5 & Caudal \\
\hline Crim1* $^{*}$ & Cysteine rich transmembrane BMP regulator 1 (chordin-like) & L5 corticospinal motor neuron & All \\
\hline Crym & Crystallin, mu & L5 corticospinal motor neuron & Caudal \\
\hline $\operatorname{Ctg}^{*}$ & Connective tissue growth factor & Subplate & All \\
\hline Ctip2 (Bcl11b) & B-cell CLL/ymphoma 11B (zinc finger protein) & L5 SCPN & All \\
\hline Cux1 & Cut-like homeobox 1 & $\llcorner 2-4$ & All \\
\hline Dtx4 & Deltex 4, E3 ubiquitin ligase & $\llcorner 2-4$ & All \\
\hline Etv1 (Er81) & Ets variant 1 & L5 & All \\
\hline Fezf2 & FEZ family zinc finger 2 & L5 SCPN & All \\
\hline Flrt3* & Fibronectin leucine rich transmembrane protein 3 & L2-3 & Caudal \\
\hline Foxp1 & Forkhead box P1 & L5 & All \\
\hline Foxp2 & Forkhead box P2 & L6 & All \\
\hline Inhba & Inhibin, beta A & L2-4, CPN & All \\
\hline Lhx 5 & LIM homeobox 5 & Cajal-Retzius & All \\
\hline Limch1 & LIM and calponin homology domains 1 & L2-3, CPN & All \\
\hline Mdga1 & MAM domain containing glycosylphosphatidylinositol anchor 1 & L2-3 & Caudal \\
\hline Mef2c & Myocyte enhancer factor 2C & L2-3 & All \\
\hline $\operatorname{Nrgn}^{*}$ & Neurogranin & $\llcorner 2-4$ & All \\
\hline Nxph4 & Neurexophilin 4 & Subplate & All \\
\hline Oma1 & OMA1 zinc metallopeptidase & L5 SCPN & All \\
\hline Pcdh11x & Protocadherin $11 \mathrm{X}$-linked & L2-4 & All \\
\hline Pcdh19 & Protocadherin 19 & L5 & All \\
\hline Pcdh20 & Protocadherin 20 & L2-4 & Rostral \\
\hline Pcdh8 & Protocadherin 8 & $\llcorner 2-3$ & Caudal \\
\hline Pcp4 & Purkinje cell protein 4 & L5 & All \\
\hline Pou3f2 (Brn-2) & POU class 3 homeobox 2 & L2-4 & All \\
\hline Pou3f3 (Brn-1) & POU class 3 homeobox 3 & L2-4 & All \\
\hline Ppp1r1b* & Protein phosphatase 1, regulatory (inhibitor) subunit 1B & L6 & Rostral \\
\hline Ptn & Pleiotrophin & CPN & All \\
\hline Ptprz1 & Protein tyrosine phosphatase, receptor-type, Z polypeptide 1 & L2-3 & Caudal \\
\hline Pvrl3 & Poliovirus receptor-related 3 & $\mathrm{~L} 2-3, \mathrm{CPN}$ & Caudomedial \\
\hline $\operatorname{Reln}^{*}$ & Reelin & Cajal-Retzius & All \\
\hline Rgs8 & Regulator of G-protein signaling 8 & L2-3 & All \\
\hline Rorb* & RAR-related orphan receptor B & $\llcorner 4$ & Rostral \\
\hline S100a10 & S100 calcium binding protein $\mathrm{A} 10$ & L5 corticospinal motor neuron & All \\
\hline
\end{tabular}


TABLE 2 | Continued

\begin{tabular}{|c|c|c|c|}
\hline Gene symbol* & Gene name & Layer & Region \\
\hline Satb2 & SATB homeobox 2 & CPN & All \\
\hline Sorl1 & Sortilin-related receptor, L(DLR class) A repeats containing & $\mathrm{L} 2-3$ & All \\
\hline Sox $5^{\star}$ & SRY (sex determining region Y)-box 5 & L6 & All \\
\hline Tle1 & Transducin-like enhancer of split 1 (E(sp1) homolog, Drosophila) & L2-3 & All \\
\hline Tle4* & Transducin-like enhancer of split 4 & L6 & All \\
\hline Tox & Thymocyte selection-associated high mobility group box & L5 & Rostromedial \\
\hline Trp73 & Tumor protein p73 & Cajal-Retzius & All \\
\hline Unc5c & Unc-5 homolog C (C. elegans) & L4 & All \\
\hline Unc5d (Svet1) & Unc-5 homolog D (C. elegans) & L2-4 & All \\
\hline Wnt7b* & Wingless-type MMTV integration site family, member 7B & L6 & All \\
\hline Wscd1 & WSC domain containing 1 & L6 & Rostral \\
\hline Zfpm2 (FOG2) & Zinc finger protein, FOG family member 2 & L6 & All \\
\hline
\end{tabular}

${ }^{\star}$ Genes also identified in our microarray analysis (Huang et al., 2014). CPN, callosal projection neurons; SCPN, subcerebral projection neurons.

laboratory are also included in our gene list (Table 2). Moreover, based on a literature search and the database of the Simons Foundation Autism Research Initiative (https:/gene.sfari.org/ autdb/Welcome.do), 23 ASD-associated genes and a dyslexia causative gene, Kiaa0319, have also been found to be regulated by TBR1. Changes in the expression of these ASD- and dyslexiaassociated genes (Table 3) provide support for the influence of TBR1 in ASDs. Tbr1 might act as master gene controlling the expression of a panel of ASD-associated genes and thus influence neural development and function (Chuang et al., 2015).

Moreover, the expression levels of 15 transcriptional regulators are reduced, while those of three transcription factors are upregulated in $\mathrm{TbrI}^{-/-}$brains compared with wild-type littermates (Table 4). These changes suggest that, in addition to directly regulating gene expression, TBR1 also controls transcriptional networks to influence neuronal development. Indeed, evidence has indicated that TBR1 directly binds to the locus of Fezf2, a layer 5-specific transcription factor, and represses Fezf2 expression in layer 6 to specify the corticothalamal projections of layer 6 neurons (Han et al., 2011; McKenna et al., 2011). The second transcriptional regulator directly controlled by TBR1 is autistic susceptibility gene2 (Auts2). TBR1 binds to the region around the Auts2 transcriptional start site and activates expression of the Auts2 gene (Bedogni et al., 2010). AUTS2 is part of polycomb repressive complex I (PRCI) that catalyzes the monoubiquitination of histone $\mathrm{H} 2 \mathrm{~A}$ and epigenetically represses gene expression, particularly during the developmental stage (de Napoles et al., 2004; Wang et al., 2004b). In contrast to the canonical role of PRCI in gene repression, the PRCI-AUST2 complex activates neuronal gene expression by recruiting casein kinase 2 and p300 to chromatin (Gao et al., 2014). The activation of Auts2 expression by TBR1 supports the influence of TBR1 on global gene expression in neurons.

In addition to using a transcriptional cascade to indirectly control gene expression, TBR1 may also alter the relative number of projection neurons and interneurons in the brain and influence the total expression levels of certain genes, such as
Gad1, which encodes glutamate decarboxylase 1 (GAD67) - an essential gene of GABAergic neurons. In Tbr1 deletion mice, the expression of Gad1 is noticeably upregulated (Chuang et al., 2015). Because Tbr1 is specifically expressed in glutamatergic projection neurons, it is possible to speculate that increased Gad1 expression is indirectly linked to a reduction in the population of glutamatergic neurons.

Consistent with the function of TBR1 in the regulation of axonal projection, TBR1 also regulates eight membrane proteins (CNTN2, CDH8, GPC6, CD44, FLRT3, CNTN6, NTNG1, and KIAA0319) that are involved in cell adhesion; although it is still unclear whether these genes are directly or indirectly regulated by TBR1 (Chuang et al., 2015). Interestingly, seven of these eight membrane proteins are upregulated in $\mathrm{Tbr}^{-/-}$brains (Table 5). Because these genes control cell adhesion and axonal growth, the impairment of axonal projection in Tbr1 deficient neurons is likely due to imbalanced cell-cell and cell-matrix interactions. Alteration of the strength of these interactions may preclude neurite growth and extension (Chuang et al., 2015).

In conclusion, TBR1 controls the expression of a series of genes that regulate cell-cell adhesion, axonal growth, neurotransmission and gene expression.

\section{TBR1 INTERACTING PROTEINS}

To date, only two proteins, CASK and FOXP2, have been identified as interacting partners with TBR1. Both CASK and FOXP2 are associated with ASDs (Samuels et al., 2007; O'roak et al., 2011). TBR1 was identified as a binding partner for CASK from a yeast two-hybrid screen using the guanylate kinase domain of CASK as bait (Hsueh et al., 2000). The C-terminal region of TBR1 is required for the interaction with CASK (Hsueh et al., 2000). CASK-a multidomain adaptor protein-is widely distributed in various subcellular compartments and interacts with more than two dozen cellular proteins (Hsueh, 2006). The interaction with CASK increases the transcriptional activity of TBR1 (Hsueh et al., 2000) by recruiting a nucleosome assembly protein CINAP (CASK interacting nucleosome assembly protein, 
TABLE 3 | TBR1 influences the expression (upregulation or downregulation) of genes associated with autism or dyslexia.

\begin{tabular}{|c|c|c|c|c|}
\hline Gene symbol & Gene name & Molecular function & Tbr1-/- vs. WT & Disease \\
\hline Cd44 & CD44 molecule (Indian blood group) & Cell adhesion & Up & Autism \\
\hline Cdh8 & Cadherin 8, type 2 & Cell adhesion & Up & Autism \\
\hline Cntn6 & Contactin 6 & Cell adhesion & Up & Autism \\
\hline Gpc6 & Glypican 6 & Cell adhesion & Up & Autism \\
\hline Ntng1 & Netrin G1 & Cell adhesion & Up & Autism \\
\hline Kiaa0319 & Hypothetical protein D130043K22 & Cell adhesion & Up & Dyslexia \\
\hline Nefl & Neurofilament, light polypeptide & Cytoskeleton & Up & Autism \\
\hline Gpd2 & Glycerol-3-phosphate dehydrogenase 2 (mitochondrial) & Enzyme & Up & Autism \\
\hline Drd1 & Dopamine receptor D1A & Neurotransmission & Down & Autism \\
\hline Gad1 & Glutamate decarboxylase 1 (brain, 67 kDa) & Neurotransmission & Up & Autism \\
\hline Grin2b & Glutamate receptor, ionotropic, N-methyl D-aspartate 2B & Neurotransmission & Down & Autism \\
\hline Baiap2 & BAl1-associated protein 2 & Signaling & Down & Autism \\
\hline Lasp1 & LIM and SH3 protein 1 & Signaling & Down & Autism \\
\hline Lypd6 & LY6/PLAUR domain containing 6 & Signaling & Down & Autism \\
\hline Ppp1r1b & Protein phosphatase 1, regulatory (inhibitor) subunit 1B & Signaling & Down & Autism \\
\hline Ptprk & Protein tyrosine phosphatase, receptor type, K & Signaling & Down & Autism \\
\hline Reln & Reelin & Signaling & Down & Autism \\
\hline Auts2 & Autism susceptibility candidate 2 & Transcription factor & Down & Autism \\
\hline Nfia & Nuclear factor I/A & Transcription factor & Down & Autism \\
\hline $\mathrm{Nr} 4 \mathrm{a} 2$ & Nuclear receptor subfamily 4, group A, member 2 & Transcription factor & Down & Autism \\
\hline Sox5 & SRY (sex determining region Y)-box 5 & Transcription factor & Down & Autism \\
\hline Slc4a10 & Solute carrier family 4, sodium bicarbonate transporter, member 10 & Transporter & Up & Autism \\
\hline Stxbp6 & Syntaxin binding protein 6 (amisyn) & Vesicle trafficking & Up & Autism \\
\hline Sv2b & Synaptic vesicle glycoprotein 2B & Vesicle trafficking & Down & Autism \\
\hline
\end{tabular}

also known as testis specific protein Y-encoded like 2, TSPYL2) to the promoter region containing the T-box DNA binding motif (Wang et al., 2004a). CINAP also interacts with the guanylate kinase domain of CASK. However, it does not compete with TBR1 for CASK binding. Instead, TBR1, CASK and CINAP form a tripartite complex to regulate Grin $2 b$ expression (Wang et al., 2004a,c). CASK is well-known as a causative gene in Xlinked mental retardation (Najm et al., 2008). The interaction of CASK and TBR1 and the consequent effect on the regulation of Grin $2 b$ expression and neural development has been suggested to contribute to the phenotype of patients with CASK mutations (Hsueh, 2009). It can also be speculated that Grin2b expression, as controlled by the TBR1-CASK complex, might also be involved in ASDs due to TBR1 or CASK mutations.

FOXP2 is a critical transcription factor that controls speech (Lai et al., 2001; Enard et al., 2002) and is also associated with ASDs (Gong et al., 2004; Li et al., 2005). In contrast to the interaction between CASK and TBR1, the interaction between TBR1 and FOXP2 is less clear. Research suggests that both the T-box and C-terminal regions of TBR1 are involved in the interaction with FOXP2 (Deriziotis et al., 2014). For FOXP2, both its $\mathrm{N}$ - and C-terminal regions contribute to the interaction between FOXP2 and TBR1 (Deriziotis et al., 2014). Although it has been speculated that the interaction of FOXP2 and TBR1 is likely relevant to the verbal deficits in ASD patients, the molecular function of the TBR1-FOXP2 interaction is unclear. Furthermore, FOXP2 and TBR1 are only coexpressed in layer 6 of the cerebral cortex and not in other layers of the cerebral cortex and amygdala. Thus, the interaction with FOXP2 can only partly account for the function of TBR1.

TBR1, its binding partners CASK and FOXP2 and its direct downstream target GRIN2B, are all associated with ASDs, reinforcing the role of TBR1 in ASDs.

\section{TBR1 MUTATIONS ASSOCIATE WITH NEUROLOGICAL DISORDERS}

Genetic analyses of patients have identified TBR1 as a highconfidence risk factor for ASDs (https://gene.sfari.org/autdb/ GSGeneList.do?c=1). Identified mutations in TBR1 genes are summarized in Figure 1. Both de novo and inherited mutations in TBR1 have been found in patients with ASDs (Figure 1). Two of the mutations, p.A136PfsX80 and p.S351X, result in early termination and generate truncated proteins that lack a functional DNA-binding T-box domain (O'roak et al., 2012a,b; De Rubeis et al., 2014). These two truncated mutants can no longer function in transcription or in interactions with CASK and FOXP2. The remaining three de novo mutations are p.K228E, p.W271C, and p.N374H (Figure 1). Based on simulations with the T-box DNA binding domain of Brachury (http://www.ncbi. nlm.nih.gov/Structure/cdd/cddsrv.cgi?uid=250216), the K228 residue is predicted to directly contribute to DNA binding (Figure 1). Thus, the p.K228E mutation is expected to disrupt 
TABLE 4 | Deletion of Tbr1 influences the expression of a panel of transcription factors in neurons.

\begin{tabular}{|c|c|c|}
\hline Gene Symbol & Tbr1-/- vs. WT & Gene name \\
\hline Bcl6 & 0.3623 & B-cell leukemia/lymphoma 6 \\
\hline $\mathrm{Nfe} 2 \mathrm{l3}$ & 0.4017 & Nuclear factor, erythroid derived 2, like 3 \\
\hline Nhlh2 & 0.4219 & Nescient helix loop helix 2 \\
\hline Sox5 & 0.4875 & $\begin{array}{l}\text { BB018032 RIKEN full-length enriched, adult male testis (DH10B) Mus musculus cDNA clone } 4930572 \mathrm{C} 183^{\prime} \text { similar to } \\
\text { AJ010604 Mus musculus mRNA for transcription factor L-Sox5, mRNA sequence. }\end{array}$ \\
\hline $\mathrm{Nr} 4 \mathrm{a} 2$ & 0.5179 & BB703394 RIKEN full-length enriched, in vitro fertilized eggs Mus musculus cDNA clone 7420451 N07 3', mRNA sequence. \\
\hline Rorb & 0.529 & RAR-related orphan receptor beta \\
\hline Tp73 & 0.5355 & Transformation related protein 73 \\
\hline Btbd11 & 0.5719 & BTB (POZ) domain containing 11 \\
\hline Tle4 & 0.5821 & Transducin-like enhancer of split 4, homolog of Drosophila E(spl) \\
\hline Rbm14 & 0.59 & RNA binding motif protein 14 \\
\hline Foxf2 & 0.5983 & Forkhead box F2 \\
\hline Tfap2c & 0.6348 & Transcription factor AP-2, gamma \\
\hline Zswim4 & 0.639 & Zinc finger, SWIM domain containing 4 \\
\hline Nfia & 0.643 & RIKEN cDNA 9430022M17 gene \\
\hline Neurod6 & 0.6644 & Neurogenic differentiation 6 \\
\hline Runx1t1 & 1.5064 & CBFA2T1 identified gene homolog (human) \\
\hline Ascl1 & 1.6328 & Achaete-scute complex homolog-like 1 (Drosophila) \\
\hline Pou3f1 & 1.6528 & POU domain, class 3 , transcription factor 1 \\
\hline
\end{tabular}

TABLE 5 | Tbr1 deletion mainly upregulates expression of cell adhesion molecules in neurons.

\begin{tabular}{lcl}
\hline Gene symbol & Tbr1-/- vs. WT & Gene name \\
\hline Cdh8 & 1.5013 & Cadherin 8 \\
Gpc6 & 1.5874 & Glypican 6 \\
Cd44 & 1.7384 & CD44 antigen \\
Flrt3 & 1.8118 & Fibronectin leucine rich transmembrane \\
& & protein 3 \\
Cntn6 & 2.0967 & Contactin 6 \\
Ntng1 & 2.3218 & Netrin G1 \\
Kiaa0319 & 2.8456 & Hypothetical protein D130043K22 \\
Cntn2 & 0.6331 & Contactin 2 \\
\hline
\end{tabular}

the DNA binding ability of TBR1. The residues $\mathrm{W} 271$ and $\mathrm{N} 374$ are adjacent to the DNA binding residues (Figure 1). Thus, the p.W271C and p.N374H mutations could alter protein conformation and indirectly influence DNA binding. The p.V356M inherited mutation is localized in the T-box, but it is relatively far from the DNA binding and dimerization motifs. The remaining inherited mutations, including p.E31Q, p.P38T, p.Q178E, p.Q418R, p.V437L, and p.P542R, are localized to the $\mathrm{N}$ - and C-terminal regions and are not known to influence DNA binding. The impact of these inherited mutations is unclear.

To date, only two studies have analyzed the effects of these ASD mutations on TBR1 function. We contributed to the first functional study, which examined axonal growth in the amygdalar neurons of the TBR1 N374H mutant (Huang et al., 2014). An experiment comparing $\mathrm{Tbr} \mathrm{I}^{+/-}$and wild-type amygdalar neurons showed that the deletion of one Tbr1 gene results in multiple and shorter axons in amygdalar neurons
(Huang et al., 2014). The reintroduction of wild-type Tbr1 into $\mathrm{Tbr}^{+/-}$amygdalar neurons effectively promotes axon growth and reduces the percentage of neurons carrying multiple axons to the levels seen in wild-type neurons. However, the N374H mutant fails to rescue the axonal defects of $\mathrm{Tbr} \mathrm{I}^{+/}-$amygdalar neurons, suggesting that the p.N374H mutation identified in patients with ASD results in a loss of function (Huang et al., 2014).

The second study focused on the effect of ASD mutations on the subcellular distribution, transcriptional activity, dimerization and protein-protein interaction of TBR1 using heterologous HEK293 cells as a model (Deriziotis et al., 2014). De novo mutations, including p.K228E and p.N374H, change the subcellular distribution of TBR1 in HEK293 cells. The mutant proteins tend to form large aggregates in the nuclei. The impact of these two mutations on the transcriptional activity of TBR1 is unclear because the luciferase reporter assay did not show a difference between the wild-type TBR1 and K228E and $\mathrm{N} 374 \mathrm{H}$ mutants. However, similar to the truncated mutants, the K228E and $\mathrm{N} 374 \mathrm{H}$ mutants no longer interact with FOXP2, which is consistent with the observation that the T-box domain is also involved in FOXP2 interactions, as described above. The mechanisms by which rare inherited mutations impair the function of TBR1 remain largely unclear, except for the p.Q418R mutation, which is known to reduce the interaction between TBR1 and FOXP2. Because TBR1 is a projection neuron-specific transcription factor, the relevance of the interaction between TBR1 and FOXP2 must be investigated in neurons instead of HEK293 cells.

In addition to ASDs, TBR1 is also associated with intellectual disability. The TBR1 locus is at chromosome 2q24.2. Both a microdeletion of the chromosome region that contains $2 \mathrm{q} 24.2$ and de novo mutations of the TBR1 gene have been found in 
patients with intellectual disabilities (Traylor et al., 2012; Burrage et al., 2013; Hamdan et al., 2014; Palumbo et al., 2014). Moreover, the expression levels of TBR1 are increased in patients that suffer from schizophrenia (Molnar et al., 2003). Taken together, TBR1 is closely associated with ASDs, schizophrenia and intellectual disability.

\section{Tbr1 HAPLOINSUFFICIENCY RESULTS IN NEURONAL DEFECTS}

In ASD patients, only one of the two TBR1 alleles is mutated (Neale et al., 2012; O'roak et al., 2012a,b; De Rubeis et al., 2014; Deriziotis et al., 2014). Several possibilities may explain the effect of TBR1 heterozygosity on brain function: haploinsufficiency or a dominant negative or gain-of-function effect of the mutated allele. Because two of the de novo mutations of the TBR1 gene, p.A136PfsX80, and p.S351X, result in early termination and generate truncated proteins that lack a full length T-box DNA binding domain and dimerization domain (Figure 1), the mutants are not expected to exert a dominant negative effect on the activity of TBR1 based on the known molecular function of TBR1. Instead, the defects are likely caused by haploinsufficiency. Tbr $1^{+/-}$neurons are characterized by shorter and multiple axons (Huang et al., 2014), indicating that loss of a copy of the Tbr1 gene results in abnormal neuronal differentiation. Thus, TBR1 deficits in patients are likely due to haploinsufficiency.

\section{Tbrit/- MICE SERVE AS A MOUSE MODEL FOR ASDS}

Because only one of two TBR1 alleles is mutated in patients with ASDs and Tbr1 heterozygosity does not influence survival and the general health of mice, $T b r 1^{+/-}$mice serve as a good animal model to elucidate the role of Tbr1 in ASDs. The core symptoms of patients with ASDs are both verbal and nonverbal communication defects, impaired social interaction and cognitive inflexibility. ASDs are also frequently associated with learning disability. A series of behavior paradigms have been applied to characterize the behavioral defects of Tbr1 (Table 6). Compared with wild-type littermates, the locomotor and

TABLE 6 | Tbr1 haploinsufficiency results in autism-like behaviors in mice.

\begin{tabular}{lll}
\hline Behavior paradigm & Assay for & $\begin{array}{l}\text { Phenotype in Tbr1+/- } \\
\text { mice }\end{array}$ \\
\hline $\begin{array}{l}\text { Conditioned taste aversion } \\
\text { Auditory fear conditioning }\end{array}$ & $\begin{array}{l}\text { Learning and memory } \\
\text { Learning and memory } \\
\text { Reverse learning }\end{array}$ & $\begin{array}{l}\text { Learning defect } \\
\text { Learning defect } \\
\text { Cognition inflexibility }\end{array}$ \\
$\begin{array}{l}\text { Two-choice digging task } \\
\text { Three-chamber test }\end{array}$ & $\begin{array}{l}\text { Reverse learning } \\
\text { Social interaction }\end{array}$ & $\begin{array}{l}\text { Cognition inflexibility } \\
\text { Poor social interaction }\end{array}$ \\
$\begin{array}{l}\text { Reciprocal social } \\
\text { interactions }\end{array}$ & Social interaction & Poor social interaction \\
$\begin{array}{l}\text { Social transmission of food } \\
\text { preference } \\
\text { Ultrasonic vocalizations }\end{array}$ & Social interaction & Poor social interaction \\
& Communication & Poor communication
\end{tabular}

exploratory activities, the level of anxiety and the hippocampusdependent memory of $\mathrm{Tbr} \mathrm{I}^{+/-}$mice are normal (Huang et al., 2014). However, the amygdala-dependent behaviors of $\mathrm{Tbr}^{+/-}$ mice are noticeably affected. Conditioned taste aversion and auditory fear conditioning - two amygdala-dependent learning and memory paradigms - are both impaired in $\mathrm{Tbr}^{+/-}$mice. Cognitive flexibility, as examined by appetitive-motivated Tmaze and two-choice digging tests, is also noticeably reduced in $\mathrm{Tbr}^{+/-}$mice. The three-chamber test, reciprocal social interactions and social transmission of food preferences have also been applied to characterize the social interactions of $\mathrm{Tbr} 1^{+/-}$ mice. These paradigms all indicate that the social interactions of $\mathrm{Tbr1}^{+/-}$mice are impaired. Moreover, the frequency of ultrasonic vocalization is significantly lower in isolated $T b r 1^{+/-}$ pups. Thus, these behavioral analyses strongly support that $\mathrm{Tbr1}^{+/-}$mice exhibit autism-like behaviors (Huang et al., 2014).

\section{DEFECTS IN AMYGDALAR CIRCUITS AND ACTIVATION ARE CRITICAL FOR ASDS CAUSED BY Tbr1 DEFICIENCY}

When Tbr1 is completely deleted from mice, the most prominent phenotypes are observed in the neuronal migration and axonal projection of the embryonic cerebral cortex (Bulfone et al., 1998; Hevner et al., 2001). However, none of these defects are found in the $\mathrm{Tbr1}^{+/-}$brain (Huang et al., 2014). Cortical lamination, contralateral cortical projection, corticothalamal projection and the size of the cerebral cortex of $T b r 1^{+/-}$brains are comparable to those of wild-type brains (Huang et al., 2014). Unexpectedly, the posterior part of the anterior commissure is either missing or dramatically reduced in $T b r 1^{+/-}$mice (Huang et al., 2014). This defect is $100 \%$ penetrant in all $\mathrm{Tbr} \mathrm{I}^{+/-}$mice. Thus, the posterior part of the anterior commissure is the structure most sensitive to Tbr1 haploinsufficiency. Consequently, defects of the posterior part of the anterior commissure are more relevant to the pathogenesis of TBR1-dependent ASDs.

The posterior part of the anterior commissure serves to connect the contralateral amygdalae (interamygdalar projections). The amygdala contains three major nuclei, namely the lateral, basal and central amygdala (Figure 2). Interamygdalar projections emerge from the lateral and basal amygdala. These two nuclei also project to the ipsilateral central amygdala (intraamygdalar projections). The lateral and basal amygdalae are the nuclei that receive inputs from the cortex, thalamus and hippocampus. To induce a freezing response, the lateral and basal amygdalae deliver the signals to the central amygdala, and the central amygdala further projects to the brainstem and hypothalamus. In addition to the central amygdala, the lateral and basal amygdalae also project back to the cortex, hippocampus, and thalamus, which are believed to regulate memory and social behavior (Lee et al., 2013; Janak and Tye, 2015). Because the amygdala is the pivotal brain structure for social intelligence, the amygdala is an obvious target for the etiology of TBR1-dependent ASDs.

The results of DiI tracing and retrograde red bead labeling show that both inter- and intra-amygdalar axonal projections 
are noticeably impaired in $\mathrm{Tbr} \mathrm{I}^{+/-}$mice (Figure 3; Huang et al., 2014). The lateral and basal amygdala neurons are the major target of Tbr1 haploinsufficiency. Consistent with the axonal projection defects in the brain, $\mathrm{Tbr} \mathrm{I}^{+/-}$amygdala neurons possess shorter and multiple axons, which suggests that Tbr1 haploinsufficiency results in a cell-autonomous effect that restricts axonal extension and differentiation (Huang et al., 2014).

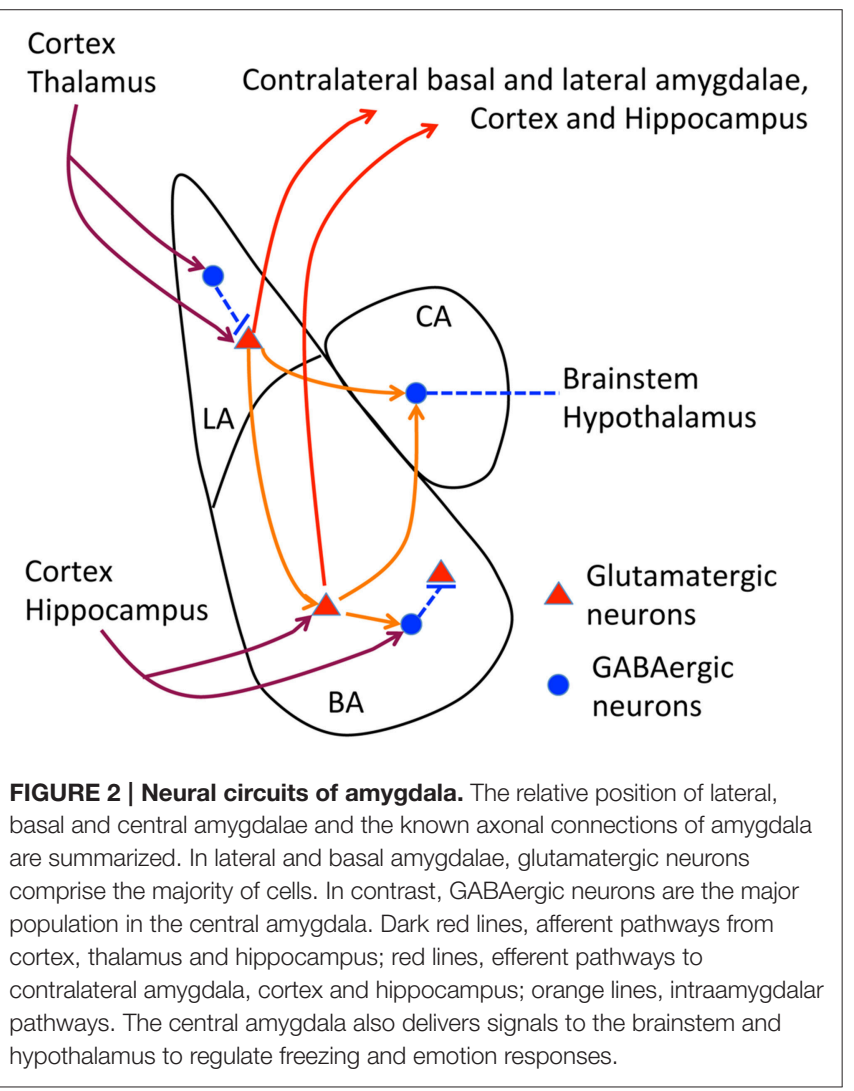

To investigate how TBR1 controls axonal growth, we examined the TBR1 downstream target genes in a gene list from our microarray data. Specifically, we examined Cntn2, Cdh8, and Ntng1 because these three genes encode adhesion proteins that regulate neurite outgrowth and fasciculation (Furley et al., 1990; Stoeckli and Landmesser, 1995; Kunz et al., 1998; Nakashiba et al., 2002; Bekirov et al., 2008). Restoring the expression levels of Cntn2, Cdh8, and Ntng1 in Tbr1 $1^{+/-}$amygdalar neurons effectively ameliorates axonal growth and differentiation in cultures and promotes axonal projection to form the posterior part of the anterior commissure in vivo. Thus, TBR1 controls the expression of a panel of genes that regulate amygdalar axonal projections. Note that although the axonal projections of lateral and basal amygdalae are significantly impaired in Tbr $1^{+/-}$brains, the size and cell density of the lateral and basal amygdalae do not differ between $T b r 1^{+/-}$mice and wild-type littermates. It is unclear whether $\mathrm{Tbr} \mathrm{I}^{+/-}$amygdalar neurons mistarget to other brain regions. More investigations are needed to characterize this regulation in detail.

Although the significance of interamygdalar connections is unclear, a reduction of intraamygdalar axonal projections implies that the amygdala is functionally impaired in $\mathrm{Tbr1} \mathrm{1}^{+/-}$mice. Indeed, neuronal activation of the amygdala is impaired in $\mathrm{Tbr1}^{+/-}$mice (Huang et al., 2014). Two amygdala-dependent learning/memory paradigms-conditioned taste aversion and auditory fear conditioning-have been used to investigate amygdalar responses. Both c-FOS and NMDAR2B protein levels were used to monitor neuronal activation in amygdalae. These experiments showed that the induction of both c-FOS and NMDAR2B are either much lower or completely absent in the lateral and basal amygdalae of $\mathrm{Tbr} \mathrm{1}^{+/-}$mice after conditioned taste aversion training and auditory fear conditioning (Huang et al., 2014; Chuang et al., 2015). Thus, both axonal projection and neuronal activation are defective in $\mathrm{Tbr} \mathrm{I}^{+/-}$amygdalae.

Possibly due to an impairment of NMDAR induction in the Tbr $1^{+/-}$amygdala, electrophysiological recording data showed
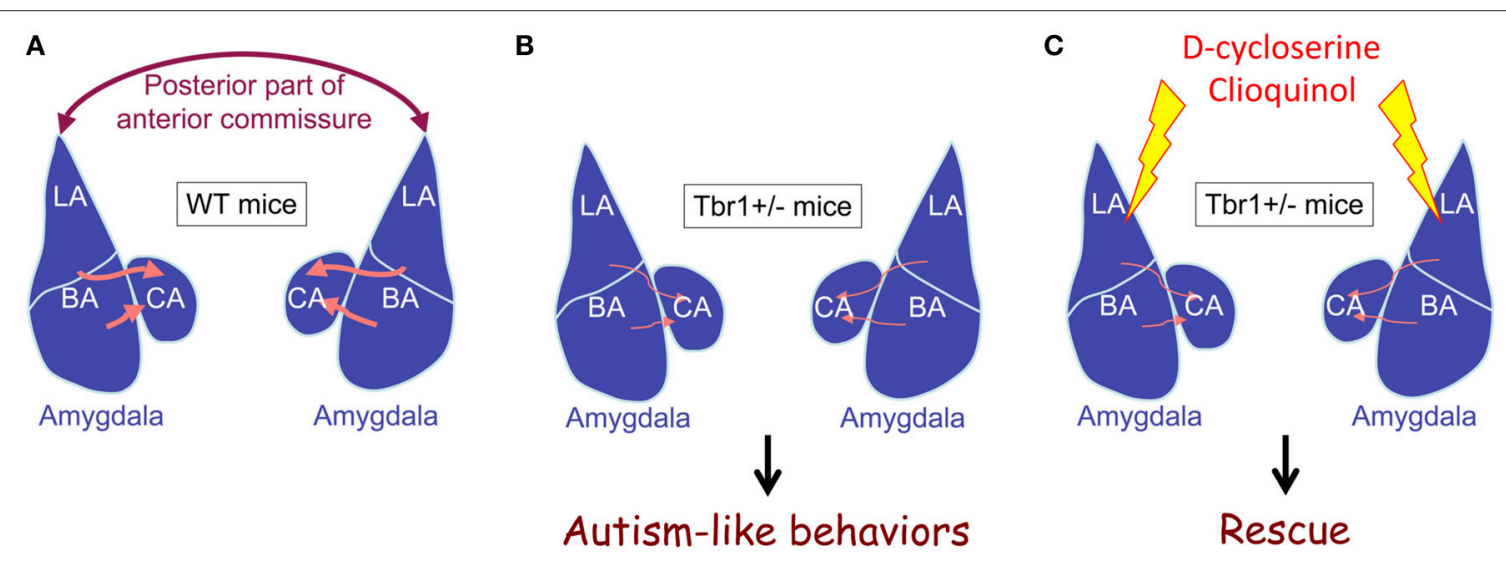

FIGURE 3 | Tbr1 haploinsufficiency results in defects of intra- and inter-amygdalar axonal projections. (A) Wild-type mice. (B) Tbr $1+/-$ mice. (C) $T b r 1+/-$ mice with D-cycloserine or clioquinol injection. The interamygdalar projection via the posterior part of the anterior commissure is significantly impaired in $T b r 1^{+} /-$mice. Intraamygdalar connections between basolateral and central amygdalae are also noticeably reduced in $\mathrm{Tbr} 1^{+/-}$mice. Tbr $1^{+/-}$mice are characterized by autism-like behaviors. Increased neuronal activity in the amygdala using either D-cycloserine or clioquinol restores behavioral defects to normal levels, although axonal projection defects are not rescued. 
that the NMDA/AMPA ratio is noticeably lower in the thalamiclateral amygdala synapses of $\mathrm{Tbr} 1^{+/-}$brains compared with those of wild-type brains (Lee et al., 2015b). Consistent with amygdala-specific defects in $\mathrm{Tbr} \mathrm{I}^{+/-}$mice, the hippocampal Schaffer collateral-CA1 pyramidal synapses do not exhibit this abnormal NMDA/AMPA ratio (Lee et al., 2015b). These electrophysiological studies clearly demonstrate a functional NMDAR deficiency in $\mathrm{Tbr}^{+/-}$amygdalae.

If impairment of amygdala activation, and particularly reduced NMDAR activity, is critical for autism-like behaviors in $\mathrm{Tbr}^{+/-}$mice, the activation of amygdalar neurons should ameliorate the behavioral defects of $\mathrm{Tbr}^{+/-}$mice. Indeed, a bilateral local infusion of D-cycloserine (a coagonist of NMDAR) into the amygdala clearly ameliorates the reciprocal social interaction and conditioned taste aversion defects seen in $\mathrm{Tbr1}^{+/-}$mice (Huang et al., 2014). D-cycloserine applied $30 \mathrm{~min}$ before the behavioral assay does not influence the expression of TBR1 target genes, suggesting the behavioral effects are mediated by an acute enhancement of NMDAR transmission. Because administration of D-cycloserine to the amygdala is sufficient to ameliorate the behavioral defects of $T b r 1^{+/-}$mice, the etiology of autism-like behaviors in $T b r 1^{+/-}$mice very likely involves amygdala defects (Huang et al., 2014).

In addition to local infusion, systemic administration of D-cycloserine via an intraperitoneal injection also effectively restores neuronal activation of the $\mathrm{TbrI}^{+/-}$amygdala and improves social interaction, cognitive inflexibility and associative memory of $\mathrm{Tbr1}^{+/-}$mice (Huang et al., 2014). These results indicate a potential therapeutic avenue for ASD patients possessing TBR1 gene mutations. Tbr $1^{+/-}$mice are not the only mouse model to have been used to demonstrate the beneficial effect of D-cycloserine. The behavioral deficits of Shank2-/-, $N \operatorname{lgn} 1^{-/-}$, and Grid1 ${ }^{-/-}$mice can also be ameliorated by systemic administration of D-cycloserine. Specifically, Dcycloserine improves social interactions in both Shank2 $2^{-/-}$and Grid1 ${ }^{-/-}$mice in a three-chamber test (Won et al., 2012; Yadav et al., 2012). Furthermore, D-cycloserine reduces the repetitive grooming behavior of $N \operatorname{lgn} 1^{-/-}$mice (Blundell et al., 2010). These three mutant mice all show NMDAR defects, which is consistent with the idea that NMDAR deficits are critical to the etiology of ASDs (Lee et al., 2015a). Improving NMDAR activity can ameliorate the behavioral defects of these mutant mice.

To further support the NMDAR deficit hypothesis in ASDs, we recently showed that by improving NMDAR activity via the administration of clioquinol, the social defects of $\mathrm{Tbr} 1^{+/-}$ mice are rescued (Lee et al., 2015b). Clioquinol is a zinc chelator and ionophore that promotes the mobilization of zinc from presynaptic vesicles to the postsynaptic site. The postsynaptic elevation of zinc activates the protein tyrosine kinase SRC and consequently enhances NMDAR activity. Systemic administration of clioquinol noticeably improves the sociability of the mutant mice in the three-chamber test. Consistent with the behavioral rescue, the defective electrophysiological responses of mutant brains are also ameliorated by clioquinol treatment. In $\mathrm{Tbr}^{+/-}$brains, clioquinol can restore the reduced NMDA/AMPA ratio of the thalamic-lateral amygdala synapses. Clioquinol treatment also shows a beneficial effect on Shank2-/- mice. It enhances the NMDAR activity of hippocampal Schaffer collateral-CA1 pyramidal synapses in Shank2 $2^{-/}$mice (Lee et al., 2015b). Even though the molecular mechanisms responsible for the NMDAR deficit differ between Tbr $1^{+/-}$and Shank2 $2^{-/-}$mice, increasing NMDAR activity via D-cycloserine or clioquinol efficiently ameliorates the behavioral defects of these two mutant mice. These data support that an NMDAR deficit is likely to be a common pathogenic mechanism of ASDs. Moreover, studies using D-cycloserine and clioquinol suggest that activation of amygdalar neurons using suitable pharmacological treatments can ameliorate the behavioral defects caused by Tbr1 haploinsufficiency, even though the axonal projection defects of the $T b r 1^{+/-}$amygdala cannot be rescued in adult animals.

\section{Tbr1 SERVES AS IMMEDIATE EARLY GENE TO CONTROL NEURONAL ACTIVATION IN MATURE NEURONS}

Although the expression levels of Tbr1 gradually decline after birth, the protein levels of TBR1 remain detectable in adult mouse brains (Hsueh et al., 2000; Hong and Hsueh, 2007). Based on the following scenario, TBR1 may also play a role in the adult brain. TBR1 regulates Grin2b expression (Wang et al., 2004a), and CASK phosphorylation by protein kinase A (PKA) enhances this regulation. CASK phosphorylation increases the interaction between TBR1 and CASK and thus upregulates Grin $2 b$ promoter activity (Huang et al., 2010). Therefore, PKA phosphorylation may increase the ability of TBR 1 to influence Grin $2 b$ expression, even though the expression levels of Tbr1 are lower in adult brains.

A study of in vitro cultured neurons unexpectedly showed that glutamate and bicuculline treatments noticeably upregulates Tbr1 expression (Chuang et al., 2014). Two to six hours after glutamate or bicuculline treatment, both the RNA and protein levels of Tbr1 are obviously increased. This induction is transient. The RNA levels of Tbr1 are decreased to basal levels $12 \mathrm{~h}$ after stimulation. This feature is shared among the cortical, hippocampal, and amygdalar neurons, although the induction of Tbr1 expression is much less pronounced in hippocampal neurons (Chuang et al., 2014). In addition to cultured neurons, behavioral stimulation also changes Tbr1 expression levels in mouse brains. When conditioned taste aversion is applied to stimulate neuronal activation, similar to $c$-Fos induction, Tbr1 RNA levels in the lateral amygdala, the insular cortex and the ventral hippocampus are also transiently increased $2 \mathrm{~h}$ after training (Chuang et al., 2014). Neuronal activation also induces Grin $2 b$ expression in vitro and in vivo, but this induction occurs several hours after that of Tbr1. Moreover, deletion of Tbr1 completely blocks Grin $2 b$ induction in culture (Chuang et al., 2014). Both NMDAR and CaMKII are required to induce Tbr1 expression (Figure 4). Thus, in addition to regulating axonal differentiation and neuronal migration during the early developmental stage, Tbr 1 also acts as an immediate early gene in response to synaptic stimulation in mature neurons, which might contribute to the etiology of TBR1-related ASDs. In particular, 


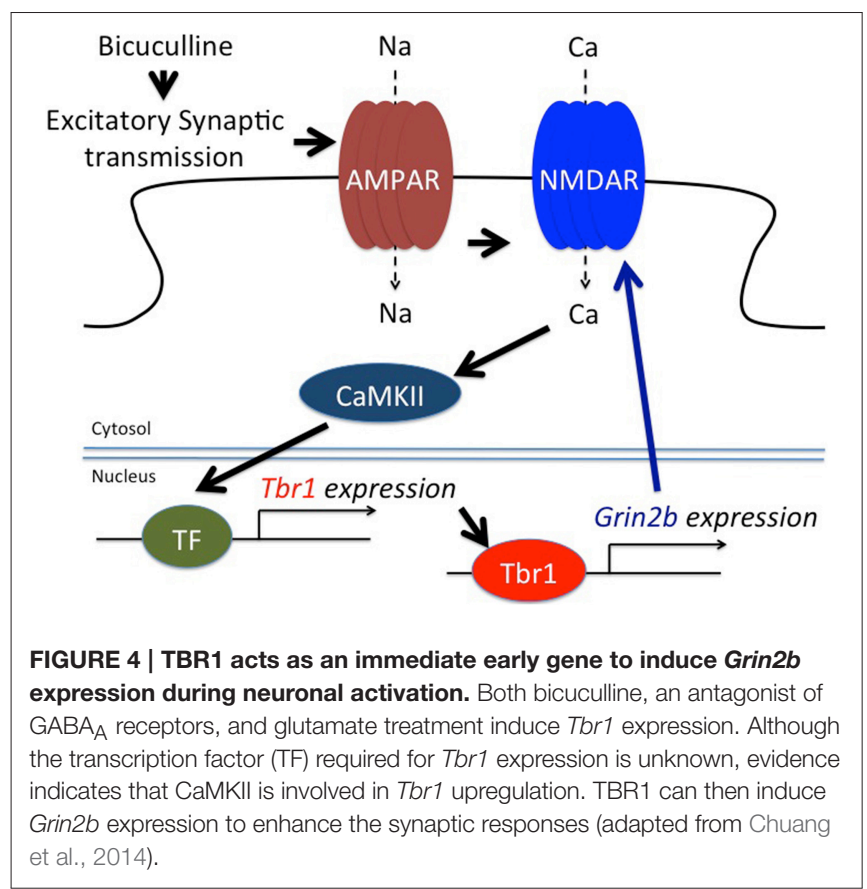

the cerebral cortex of $\mathrm{Tbr} 1^{+/-}$mice likely exhibits defective electrophysiological responses and thus influences behaviors, even though anatomic defects of the cerebral cortex have not been identified in $\mathrm{Tbr}^{+/-}$mice. More investigations need to be conducted to address this possibility.

\section{ABNORMAL BRAIN WIRING AND EXCITATION/INHIBITION IMBALANCE-TWO PROMINENT MODELS FOR THE PATHOGENIC MECHANISM OF ASDs}

Although the etiology of ASDs is heterogeneous, the two most prominent models for autism pathogenesis in the literature are abnormal brain wiring and an imbalance of neuronal activity (excitatory/inhibitory imbalance; Rubenstein and Merzenich, 2003; Walsh et al., 2008; Bernardinelli et al., 2014; Cellot and Cherubini, 2014; Deidda et al., 2014). These two defects lead to abnormal information processing and result in autism-like behaviors. These two models are interconnected to a certain extent. During neurodevelopment, neurons must extend their axons and form synapses with their target neurons, which allows the activity of the downstream target neurons to be regulated. In the absence of correct excitatory or inhibitory inputs, the activity of target neurons will be either too low or too high. These inappropriate levels of neuronal activity result in abnormal information processing, which leads to aberrant behaviors. Moreover, the imbalanced activity of neurons also influences (either strengthens or attenuates) their connections to other neurons. When the connection is too weak, it may be eliminated, which may alter brain wiring. In the $T b r 1^{+/-}$mouse model, amygdalar axonal projections are defective. Both inter- and intraamygdalar connections are noticeably impaired. Moreover, the NMDAR activity of amygdalar neurons is also much lower in Tbr1 $1^{+/-}$brains. Thus, Tbr1 $1^{+/-}$brains are characterized by both abnormal brain wiring and defective neuronal activation. Further investigation is required to see whether one deficit contributes more substantially to ASD pathology.

\section{CONCLUDING REMARKS}

Tbr $1^{+/-}$mice constitute the first genetic mouse model to show that defects in amygdalar circuits and activity result in autism-like behaviors. TBR1 controls the expression of a panel of genes that is associated with ASDs. TBR1 regulates axonal growth and the neuronal activation of amygdalar neurons by regulating downstream genes. Enhancing NMDAR activation with D-cycloserine and clioquinol to increase neuronal activity can ameliorate the behavioral defects of $\mathrm{Tbr} 1^{+/-}$mice, although the anatomic defects caused by Tbr1 haploinsufficiency are not rescued. $T b r 1^{+/-}$mice thereby serve as a model to elucidate how mutation of an autism causative gene influences brain wiring and impairs neuronal activity and consequently results in autismlike behaviors. Nevertheless, several issues remain unresolved. First, why is the amygdala the brain structure most sensitive to Tbr1 haploinsufficiency? Second, since Tbr1 $1^{+/-}$amygdalar neurons do not correctly form inter- and intra-amygdalar connections, a study of the mistargeting of $T b r 1^{+/-}$amygdalar axons might further illustrate the neural circuit defects caused by Tbr1 haploinsufficiency. Third, although the anatomical features of the cerebral cortex of $T b r 1^{+/-}$mice are normal, the electrophysiological responses of the $\mathrm{Tbr} \mathrm{I}^{+/-}$cerebral cortex remain to be measured. Fourth, the TBR1 downstream genes have not been annotated in detail. Only four TBR1 direct target genes have so far been identified. Further work is necessary to understand the individual actions of other TBR1 downstream target genes and how their dysfunction could generate autismlike behaviors. Finally, it is unclear how TBR1 functions as a transcriptional activator in some cases but acts as a repressor in others. This phenomenon also deserves further investigation. Addressing these questions will further elucidate the roles of TBR1 in brains and potentially impact on autism research.

\section{AUTHOR CONTRIBUTIONS}

Both $\mathrm{YH}$ and $\mathrm{TH}$ wrote the manuscript and prepared the tables and figures.

\section{ACKNOWLEDGMENTS}

This work was supported by grants from Academia Sinica (AS-103-TP-B05) and the Ministry of Science and Technology (MOST 103-2321-B-001-002, 103-2321-B-001-018, and 1042321-B-001-050) to YH. TH is supported by a Postdoctoral Fellowship from Academia Sinica. 


\section{REFERENCES}

Bedogni, F., Hodge, R. D., Elsen, G. E., Nelson, B. R., Daza, R. A., Beyer, R. P., et al. (2010). Tbrl regulates regional and laminar identity of postmitotic neurons in developing neocortex. Proc. Natl. Acad. Sci. U.S.A. 107, 13129-13134. doi: $10.1073 /$ pnas. 1002285107

Bekirov, I. H., Nagy, V., Svoronos, A., Huntley, G. W., and Benson, D. L. (2008). Cadherin- 8 and N-cadherin differentially regulate pre- and postsynaptic development of the hippocampal mossy fiber pathway. Hippocampus 18, 349-363. doi: 10.1002/hipo.20395

Bernardinelli, Y., Nikonenko, I., and Muller, D. (2014). Structural plasticity: mechanisms and contribution to developmental psychiatric disorders. Front. Neuroanat. 8:123. doi: 10.3389/fnana.2014.00123

Blundell, J., Blaiss, C. A., Etherton, M. R., Espinosa, F., Tabuchi, K., Walz, C., et al. (2010). Neuroligin-1 deletion results in impaired spatial memory and increased repetitive behavior. J. Neurosci. 30, 2115-2129. doi: 10.1523/JNEUROSCI.451709.2010

Bulfone, A., Smiga, S. M., Shimamura, K., Peterson, A., Puelles, L., and Rubenstein, J. L. (1995). T-brain-1: a homolog of Brachyury whose expression defines molecularly distinct domains within the cerebral cortex. Neuron 15, 63-78. doi: 10.1016/0896-6273(95)90065-9

Bulfone, A., Wang, F., Hevner, R., Anderson, S., Cutforth, T., Chen, S., et al. (1998). An olfactory sensory map develops in the absence of normal projection neurons or GABAergic interneurons. Neuron 21, 1273-1282. doi: 10.1016/S08966273(00)80647-9

Burrage, L. C., Eble, T. N., Hixson, P. M., Roney, E. K., Cheung, S. W., and Franco, L. M. (2013). A mosaic 2q24.2 deletion narrows the critical region to a $0.4 \mathrm{Mb}$ interval that includes TBR1, TANK, and PSMD14. Am. J. Med. Genet. A 161A, 841-844. doi: 10.1002/ajmg.a.35751

Cellot, G., and Cherubini, E. (2014). GABAergic signaling as therapeutic target for autism spectrum disorders. Front Pediatr 2:70. doi: 10.3389/fped.2014.00070

Chuang, H. C., Huang, T. N., and Hsueh, Y. P. (2014). Neuronal excitation upregulates Tbrl, a high-confidence risk gene of autism, mediating Grin2b expression in the adult brain. Front. Cell. Neurosci. 8:280. doi: $10.3389 /$ fncel.2014.00280

Chuang, H. C., Huang, T. N., and Hsueh, Y. P. (2015). T-Brain-1 - A Potential Master Regulator in Autism Spectrum Disorders. Autism Res. 8:412. doi: 10.1002/aur.1456

Deidda, G., Bozarth, I. F., and Cancedda, L. (2014). Modulation of GABAergic transmission in development and neurodevelopmental disorders: investigating physiology and pathology to gain therapeutic perspectives. Front. Cell. Neurosci. 8:119. doi: 10.3389/fncel.2014.00119

de Napoles, M., Mermoud, J. E., Wakao, R., Tang, Y. A., Endoh, M., Appanah, R., et al. (2004). Polycomb group proteins Ring1 A/B link ubiquitylation of histone $\mathrm{H} 2 \mathrm{~A}$ to heritable gene silencing and X inactivation. Dev. Cell 7, 663-676. doi: 10.1016/j.devcel.2004.10.005

Deriziotis, P., O'roak, B. J., Graham, S. A., Estruch, S. B., Dimitropoulou, D., Bernier, R. A., et al. (2014). De novo TBR1 mutations in sporadic autism disrupt protein functions. Nat. Commun. 5, 4954. doi: 10.1038/ncomms5954

De Rubeis, S., He, X., Goldberg, A. P., Poultney, C. S., Samocha, K., Cicek, A. E., et al. (2014). Synaptic, transcriptional and chromatin genes disrupted in autism. Nature 515, 209-215. doi: 10.1038/nature13772

Enard, W., Przeworski, M., Fisher, S. E., Lai, C. S., Wiebe, V., Kitano, T., et al. (2002). Molecular evolution of FOXP2, a gene involved in speech and language. Nature 418, 869-872. doi: 10.1038/nature01025

Furley, A. J., Morton, S. B., Manalo, D., Karagogeos, D., Dodd, J., and Jessell, T. M. (1990). The axonal glycoprotein TAG-1 is an immunoglobulin superfamily member with neurite outgrowth-promoting activity. Cell 61, 157-170. doi: 10.1016/0092-8674(90)90223-2

Gao, Z., Lee, P., Stafford, J. M., von Schimmelmann, M., Schaefer, A., and Reinberg, D. (2014). An AUTS2-Polycomb complex activates gene expression in the CNS. Nature 516, 349-354. doi: 10.1038/nature13921

Gilman, S. R., Iossifov, I., Levy, D., Ronemus, M., Wigler, M., and Vitkup, D. (2011). Rare de novo variants associated with autism implicate a large functional network of genes involved in formation and function of synapses. Neuron 70 , 898-907. doi: 10.1016/j.neuron.2011.05.021

Gong, X., Jia, M., Ruan, Y., Shuang, M., Liu, J., Wu, S., et al. (2004). Association between the FOXP2 gene and autistic disorder in Chinese population. Am.
J. Med. Genet. B Neuropsychiatr. Genet. 127B, 113-116. doi: 10.1002/ajmg.b. 20162

Hamdan, F. F., Srour, M., Capo-Chichi, J. M., Daoud, H., Nassif, C., Patry, L., et al. (2014). De novo mutations in moderate or severe intellectual disability. PLoS Genet. 10:e1004772. doi: 10.1371/journal.pgen.1004772

Han, W., Kwan, K. Y., Shim, S., Lam, M. M., Shin, Y., Xu, X., et al. (2011). TBR1 directly represses Fezf2 to control the laminar origin and development of the corticospinal tract. Proc. Natl. Acad. Sci. U.S.A. 108, 3041-3046. doi: 10.1073/pnas. 1016723108

Hevner, R. F., Shi, L., Justice, N., Hsueh, Y., Sheng, M., Smiga, S., et al. (2001). Tbr1 regulates differentiation of the preplate and layer 6. Neuron 29, 353-366. doi: 10.1016/S0896-6273(01)00211-2

Hong, C. J., and Hsueh, Y. P. (2007). Cytoplasmic distribution of T-box transcription factor Tbr-1 in adult rodent brain. J. Chem. Neuroanat. 33, 124-130. doi: 10.1016/j.jchemneu.2007.01.005

Hsueh, Y. P. (2006). The role of the MAGUK protein CASK in neural development and synaptic function. Curr. Med. Chem. 13, 1915-1927. doi: 10.2174/092986706777585040

Hsueh, Y. P. (2009). Calcium/calmodulin-dependent serine protein kinase and mental retardation. Ann. Neurol. 66, 438-443. doi: 10.1002/ana.21755

Hsueh, Y. P., Wang, T. F., Yang, F. C., and Sheng, M. (2000). Nuclear translocation and transcription regulation by the membrane-associated guanylate kinase CASK/LIN-2. Nature 404, 298-302. doi: 10.1038/35005118

Huang, T. N., Chang, H. P., and Hsueh, Y. P. (2010). CASK phosphorylation by PKA regulates the protein-protein interactions of CASK and expression of the NMDAR2b gene. J. Neurochem. 112, 1562-1573. doi: 10.1111/j.14714159.2010.06569.x

Huang, T. N., Chuang, H. C., Chou, W. H., Chen, C. Y., Wang, H. F., Chou, S. J., et al. (2014). Tbr1 haploinsufficiency impairs amygdalar axonal projections and results in cognitive abnormality. Nat. Neurosci. 17, 240-247. doi: $10.1038 / \mathrm{nn} .3626$

Iossifov, I., O'roak, B. J., Sanders, S. J., Ronemus, M., Krumm, N., Levy, D., et al. (2014). The contribution of de novo coding mutations to autism spectrum disorder. Nature 515, 216-221. doi: 10.1038/nature13908

Janak, P. H., and Tye, K. M. (2015). From circuits to behaviour in the amygdala. Nature 517, 284-292. doi: 10.1038/nature14188

Kunz, S., Spirig, M., Ginsburg, C., Buchstaller, A., Berger, P., Lanz, R., et al. (1998). Neurite fasciculation mediated by complexes of axonin- 1 and $\mathrm{Ng}$ cell adhesion molecule. J. Cell Biol. 143, 1673-1690. doi: 10.1083/jcb.143.6.1673

Lai, C. S., Fisher, S. E., Hurst, J. A., Vargha-Khadem, F., and Monaco, A. P. (2001). A forkhead-domain gene is mutated in a severe speech and language disorder. Nature 413, 519-523. doi: 10.1038/35097076

Lee, E. J., Choi, S. Y., and Kim, E. (2015a). NMDA receptor dysfunction in autism spectrum disorders. Curr. Opin. Pharmacol. 20, 8-13. doi: 10.1016/j.coph.2014.10.007

Lee, E. J., Lee, H., Huang, T. N., Chung, C., Shin, W., Kim, K., et al. (2015b). Trans-synaptic zinc mobilization improves social interaction in two mouse models of autism through NMDAR activation. Nat. Commun. 6, 7168. doi: $10.1038 /$ ncomms 8168

Lee, S., Kim, S. J., Kwon, O. B., Lee, J. H., and Kim, J. H. (2013). Inhibitory networks of the amygdala for emotional memory. Front. Neural Circuits 7:129. doi: $10.3389 /$ fncir.2013.00129

Li, H., Yamagata, T., Mori, M., and Momoi, M. Y. (2005). Absence of causative mutations and presence of autism-related allele in FOXP2 in Japanese autistic patients. Brain Dev. 27, 207-210. doi: 10.1016/j.braindev.2004.06.002

Martinez-Cerdeno, V., and Noctor, S. C. (2014). Cajal, Retzius, and Cajal-Retzius cells. Front. Neuroanat. 8:48. doi: 10.3389/fnana.2014.00048

McKenna, W. L., Betancourt, J., Larkin, K. A., Abrams, B., Guo, C., Rubenstein, J. L., et al. (2011). Tbr1 and Fezf2 regulate alternate corticofugal neuronal identities during neocortical development. J. Neurosci. 31, 549-564. doi: 10.1523/JNEUROSCI.4131-10.2011

Molnar, M., Potkin, S. G., Bunney, W. E., and Jones, E. G. (2003). MRNA expression patterns and distribution of white matter neurons in dorsolateral prefrontal cortex of depressed patients differ from those in schizophrenia patients. Biol. Psychiatry 53, 39-47. doi: 10.1016/S0006-3223(02) 01456-7

Najm, J., Horn, D., Wimplinger, I., Golden, J. A., Chizhikov, V. V., Sudi, J., et al. (2008). Mutations of CASK cause an X-linked brain malformation phenotype 
with microcephaly and hypoplasia of the brainstem and cerebellum. Nat. Genet. 40, 1065-1067. doi: 10.1038/ng.194

Nakashiba, T., Nishimura, S., Ikeda, T., and Itohara, S. (2002). Complementary expression and neurite outgrowth activity of netrin-G subfamily members. Mech. Dev. 111, 47-60. doi: 10.1016/S0925-4773(01)00600-1

Neale, B. M., Kou, Y., Liu, L., Ma’ayan, A., Samocha, K. E., Sabo, A., et al. (2012). Patterns and rates of exonic de novo mutations in autism spectrum disorders. Nature 485, 242-245. doi: 10.1038/nature11011

Ohshima, T. (2014). Neuronal migration and protein kinases. Front. Neurosci. 8:458. doi: $10.3389 /$ fnins. 2014.00458

O'roak, B. J., Deriziotis, P., Lee, C., Vives, L., Schwartz, J. J., Girirajan, S., et al. (2011). Exome sequencing in sporadic autism spectrum disorders identifies severe de novo mutations. Nat. Genet. 43, 585-589. doi: 10.1038/ng.835

O'roak, B. J., Vives, L., Fu, W., Egertson, J. D., Stanaway, I. B., Phelps, I. G., et al. (2012a). Multiplex targeted sequencing identifies recurrently mutated genes in autism spectrum disorders. Science 338, 1619-1622. doi: $10.1126 /$ science. 1227764

O'roak, B. J., Vives, L., Girirajan, S., Karakoc, E., Krumm, N., Coe, B. P., et al. (2012b). Sporadic autism exomes reveal a highly interconnected protein network of de novo mutations. Nature 485, 246-250. doi: 10.1038/nature 10989

Palumbo, O., Fichera, M., Palumbo, P., Rizzo, R., Mazzolla, E., Cocuzza, D. M., et al. (2014). TBR1 is the candidate gene for intellectual disability in patients with a 2q24.2 interstitial deletion. Am. J. Med. Genet. A 164A, 828-833. doi: 10.1002/ajmg.a.36363

Papaioannou, V. E. (2014). The T-box gene family: emerging roles in development, stem cells and cancer. Development 141, 3819-3833. doi: 10.1242/dev.104471

Remedios, R., Huilgol, D., Saha, B., Hari, P., Bhatnagar, L., Kowalczyk, T., et al. (2007). A stream of cells migrating from the caudal telencephalon reveals a link between the amygdala and neocortex. Nat. Neurosci. 10, 1141-1150. doi: $10.1038 / \mathrm{nn} 1955$

Rubenstein, J. L., and Merzenich, M. M. (2003). Model of autism: increased ratio of excitation/inhibition in key neural systems. Genes Brain Behav. 2, 255-267. doi: 10.1034/j.1601-183X.2003.00037.x

Samuels, B. A., Hsueh, Y. P., Shu, T., Liang, H., Tseng, H. C., Hong, C. J., et al. (2007). Cdk5 promotes synaptogenesis by regulating the subcellular distribution of the MAGUK family member CASK. Neuron 56, 823-837. doi: 10.1016/j.neuron.2007.09.035
Sekine, K., Kubo, K., and Nakajima, K. (2014). How does Reelin control neuronal migration and layer formation in the developing mammalian neocortex? Neurosci. Res. 86, 50-58. doi: 10.1016/j.neures.2014.06.004

Stoeckli, E. T., and Landmesser, L. T. (1995). Axonin-1, Nr-CAM, and Ng-CAM play different roles in the in vivo guidance of chick commissural neurons. Neuron 14, 1165-1179. doi: 10.1016/0896-6273(95)90264-3

Traylor, R. N., Dobyns, W. B., Rosenfeld, J. A., Wheeler, P., Spence, J. E., Bandholz, A. M., et al. (2012). Investigation of TBR1 hemizygosity: four individuals with 2q24 microdeletions. Mol. Syndromol. 3, 102-112. doi: 10.1159/000342008

Walsh, C. A., Morrow, E. M., and Rubenstein, J. L. (2008). Autism and brain development. Cell 135, 396-400. doi: 10.1016/j.cell.2008.10.015

Wang, G. S., Hong, C. J., Yen, T. Y., Huang, H. Y., Ou, Y., Huang, T. N., et al. (2004a). Transcriptional modification by a CASK-interacting nucleosome assembly protein. Neuron 42 , 113-128. doi: 10.1016/S0896-6273(04)00139-4

Wang, H., Wang, L., Erdjument-Bromage, H., Vidal, M., Tempst, P., Jones, R. S., et al. (2004b). Role of histone H2A ubiquitination in Polycomb silencing. Nature 431, 873-878. doi: 10.1038/nature02985

Wang, T. F., Ding, C. N., Wang, G. S., Luo, S. C., Lin, Y. L., Ruan, Y., et al. (2004c). Identification of Tbr-1/CASK complex target genes in neurons. J. Neurochem. 91, 1483-1492. doi: 10.1111/j.1471-4159.2004.02845.x

Won, H., Lee, H. R., Gee, H. Y., Mah, W., Kim, J. I., Lee, J., et al. (2012). Autisticlike social behaviour in Shank2-mutant mice improved by restoring NMDA receptor function. Nature 486, 261-265. doi: 10.1038/nature11208

Yadav, R., Gupta, S. C., Hillman, B. G., Bhatt, J. M., Stairs, D. J., and Dravid, S. M. (2012). Deletion of glutamate delta-1 receptor in mouse leads to aberrant emotional and social behaviors. PLOS ONE 7:e32969. doi: 10.1371/journal.pone.0032969

Conflict of Interest Statement: The authors declare that the research was conducted in the absence of any commercial or financial relationships that could be construed as a potential conflict of interest.

Copyright $\odot 2015$ Huang and Hsueh. This is an open-access article distributed under the terms of the Creative Commons Attribution License (CC BY). The use, distribution or reproduction in other forums is permitted, provided the original author(s) or licensor are credited and that the original publication in this journal is cited, in accordance with accepted academic practice. No use, distribution or reproduction is permitted which does not comply with these terms. 